\title{
Determination of Voltage Stabilityin Distribution Network Using ANN Technique
}

\author{
Partha Kayal ${ }^{1}$, Sayonsom Chanda ${ }^{2}$, and C. K. Chanda ${ }^{3}$ \\ ${ }^{1,3}$ Department of Electrical Engineering, Bengal Engineering \& Science University, Shibpur, India \\ ${ }^{2}$ Department of Electrical Engineering, National Institute of Technology, Durgapur, India \\ 11partha_kayal@yahoo.co.in, ${ }^{2}$ ssc.nitdgp@gmail.com ${ }^{3}$,ckc_math@yahoo.com
}

\begin{abstract}
Voltage stability condition, reliability and service quality are the important parameters of a distribution system which need to be satisfied from the customer point of view.To measure voltage stability of distribution network a voltage stability index is presented in this paper. Voltage stability improvement of network is facilated by network reconfiguration and voltage stability level is quantified by voltage stability index. Network reconfiguration is a process which alters the feeder topological structure by changing the open/close status of the sectionalizing (normally closed) and ties switches (normally open) in the system. In this work, a two stage search of switching option i.e. local search and global search is implemented to achieve desired network configuration. A multilayer ANN model with Error Back Propagation Learning (EBPL) algorithm is simulated for global search to obtained optimal set of candidate switching. The proposed scheme is tested on an $11 \mathrm{kV}$ practical radial distribution system consisting of 52 buses. After reconfiguration, better voltage stable condition of the system is attained. Active power loss of the system is reduced from $0.854 \mathrm{MW}$ to 0.485 MW and reactive power loss of the system is reduced from 0.355MVar to $0.199 \mathrm{MVar}$ after achieving optimal configuration.
\end{abstract}

Keywords: Voltage stability index, Network reconfiguration, Optimal switching option, ANN, Active and reactive power losses

\section{Introduction}

Around the world energy distribution utilities are confronting to operate their distribution system as efficiently as possible by improving voltage stability of the system and minimizing distribution power losses $[1,12,15]$. Almost $30 \%$ of the total investment in power sector goes to distribution system. Mostly distribution systems are operated with radial structure for effective coordination of their protective systems and for reduction of fault levels. Voltage stability analysis of distribution system $[5,14]$ are dealt seriously as poor voltage stability may lead to voltage collapse and hence outage and gradually total black out of system. Voltage stability can be measured by voltage stability index or by voltage collapse proximity indicator $[3,5]$. Network reconfiguration process $[2,7,12,13]$ is applied in distribution networkfor improving reliability and efficiency of the system. Network reconfiguration technique is based on changing ON/OFF status of sectionalize/tie switches. Normally, network reconfiguration is implemented by closing a single tie switch and opening a sectionalize switch to preserve the radial structure of the feeders.

Now a day,there is an increasing trend to automate the distribution system. Automation is possible due to the application of dedicated software and algorithm that help the operator in selecting appropriate control actions. Network reconfiguration is a complex combinatorial optimization problem due to high number of candidate switching combinations in the system. Most of the algorithm used to solve reconfiguration problem are based on conventional optimization approaches, heuristic techniques and artificial intelligence techniques[7, 9, 10]. Joong-Rin Shin et al [10] have described a voltage stability criterion for radial distribution network. C. K. Chanda et al have studied on a voltage security indicator for longitudinal power

Received: July $13^{\text {th }}, 2011$. Accepted: March $20^{\text {th }}, 2012$ 
system [3]. M. A. Kashem et al have proposed a minimal tree search method to reconfigure distribution system [12].M. E. Baran and Wu developed a heuristic algorithm based on branch exchange method for network reconfiguration [13]. B. Vankatesh et al [2] have reported a work on optimal reconfiguration using Fuzzy adaption of evolutionary programming technique. They have also derived the maximum loadability index for radial distribution system. K. Nara et al used Genetic Algorithm for loss minimum distribution system reconfiguration [11].Few works like $\mathrm{H}$. Kim et al has focused on optimal configuration of distribution network using ANN for distribution loss minimization [7]. An ANN based feeder reconfiguration technique has also suggested by H. Salazar [8].

A voltage stability index is derived here to measure the voltage stability level of the whole distribution system. To obtain a better voltage stable system a two stage search of switching combination i.e. local search and global search of candidate switching are employed. For global search of switching option ANN algorithm is applied. Different case studies with random variations of loads are analyzed here to show the effectiveness of the proposed voltage stability index to measure voltage stability condition of the system properly.

\section{Formulation of Voltage Stability Index}

System operators would always like to know how far the network is from voltage collapse point for smooth and reliable operation of power system. In this paper a new voltage stability index is formulated which can assess the state of a distribution system from the view point voltage collapse. It is based on a simple solution of quadratic equation. Any branch $r_{i}+j x_{i}$ between bus:i and bus:i+1 of the radial distribution system may be represented by an equivalent circuit model as in Figure.1.

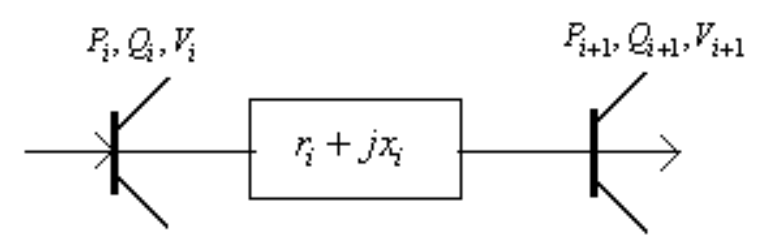

Figure 1. Two bus power system network

$$
\begin{aligned}
& I^{2}=\left(P_{i+1}^{2}+Q_{i+1}^{2}\right) / V_{i+1}^{2} \\
& I^{2}=\frac{P_{L}^{2}+Q_{L}^{2}}{\left(V_{i}-V_{i+1}\right)^{2}}
\end{aligned}
$$

Here $P_{L}$ and $Q_{L}$ are respectively active and reactive power loss of the line connected between two buses.

So, from equation (1) and (2),

$$
\begin{aligned}
& \frac{P_{i+1}^{2}+Q_{i+1}^{2}}{V_{i+1}^{2}}=\frac{P_{L}^{2}+Q_{L}^{2}}{\left(V_{i}-V_{i+1}\right)^{2}} \\
& \text { Now } P_{i+1}=P_{i}-P_{L} \\
& Q_{i+1}=Q_{i}-Q_{L}
\end{aligned}
$$




$$
\begin{gathered}
P_{L}=r_{i}\left(\frac{P_{i+1}^{2}+Q_{i+1}^{2}}{V_{i+1}^{2}}\right) \\
Q_{L}=x_{i}\left(\frac{P_{i+1}^{2}+Q_{i+1}^{2}}{V_{i+1}^{2}}\right)
\end{gathered}
$$

As the value of $P_{L}$ and $Q_{L}$ from equation (6) and (7) have used in equation (3)

$$
\left(V_{i} \cdot V_{i+1}-V_{i+1}^{2}\right)^{2}=\left(P_{i+1}^{2}+Q_{i+1}^{2}\right) \cdot\left(r_{i}^{2}+x_{i}^{2}\right)
$$

Since the positive root of the equation (8) is taken,

$$
V_{i+1}^{2}-V_{i+1} \cdot V_{i}+\sqrt{\left(\left(P_{i+1}^{2}+Q_{i+1}^{2}\right) \cdot\left(r_{i}^{2}+x_{i}^{2}\right)\right)}=0
$$

The roots of the equation (9) are real if

$$
V_{i}^{2}-4 \cdot \sqrt{\left(\left(P_{i+1}^{2}+Q_{i+1}^{2}\right) \cdot\left(r_{i}^{2}+x_{i}^{2}\right)\right)} \geq 0
$$

From equation (10) the developed Voltage Stability Index (VSI) is given as

$$
L_{i}=\frac{4 \cdot \sqrt{\left(\left(P_{i+1}^{2}+Q_{i+1}^{2}\right) \cdot\left(r_{i}^{2}+x_{i}^{2}\right)\right)}}{V_{i}^{2}} \leq 1
$$

From previous formula, it is cleared that the system is closet to voltage collapse when the value of voltage stability index approaches unity. On the other hand, the more the value of the indicator close to zero, the system is more stable.

Any interconnected network can be reduced to an equivalent two-bus network by keeping the sending end voltage constant and considering $P_{S}$ and $Q_{S}$ as total active and reactive power generation respectively connected with receiving end active and reactive load, $P_{R}$ and $Q_{R}$ respectively by an equivalent impedance of $r_{e q}+j x_{e q}$.

The power flow equations for the equivalent two-bus system are given by

$$
\begin{aligned}
& P_{S}=P_{L}+P_{R} \\
& Q_{S}=Q_{L}+Q_{R}
\end{aligned}
$$

The real power loss $P_{L}$ and reactive power loss $Q_{L}$ for the equivalent system can be represented by

$$
\begin{aligned}
& P_{L}=r_{e q}\left(\frac{P_{S}^{2}+Q_{S}^{2}}{V_{i}^{2}}\right) \\
& Q_{L}=x_{e q}\left(\frac{P_{S}^{2}+Q_{S}^{2}}{V_{i}^{2}}\right)
\end{aligned}
$$


Where $r_{e q}$ and $x_{e q}$ are the equivalent resistance and reactance of the system. Here, $V_{i}(1.0$ p.u $)$ is the sending end voltage.

The equivalent impedance of the system is given by

$$
\begin{gathered}
Z_{e q}=r_{e q}+j x_{e q} \\
r_{e q}=\frac{P_{L}}{\left(P_{S}^{2}+Q_{S}^{2}\right)} \\
x_{e q}=\frac{Q_{L}}{\left(P_{S}^{2}+Q_{S}^{2}\right)}
\end{gathered}
$$

When developed VSI is applied to the two-bus equivalent system of the multi-bus system, it can be represented as

$$
L=4 \cdot \sqrt{\left(\left(P_{R}^{2}+Q_{R}^{2}\right) \cdot\left(r_{e q}^{2}+x_{e q}^{2}\right)\right)}
$$

Thus, voltage stability level of the total interconnected system can be measured using proposed VSI and thereby appropriate action may be taken if the value of index would become nearer to unity.

\section{Network Reconfiguration and Local Search}

Network reconfiguration is an operational problem which determines the switching options that can give an optimal configuration of distribution network. The optimal configuration of network is obtained by changing the state of network switches in such way that it generates the most voltage stable system with maintaining 'radiality' of the network. This method is very attractive because it operates only on closing of tie switches or Normally Open (NO) switches and opening of sectionalize switches or Normally Closed (NC) switches already existent in the system, irrespective of any additional cost for utility.

Local Search: Solutions of network reconfiguration problem starts with initial configuration with all NO switches are in open position. With the help of load flow solution program, voltage stability of the whole system is calculated using developed VSI. In local search method different loops are studied separately with closing of NO switch and opening of NC switch at a time for the corresponding loop. Different NC switches are opened in a sequence such that radial structure will be maintained. The best set of local search switching option is occurred for maximum voltage stable system i.e.minimum value for VSI for a particular loop. Proceeding in these way different sets of switching combination can be found for different loops to improve voltage stability.

\section{Ann Model and Global Search}

Artificial Neural Network is a powerful information processing system with ability to make sensible decision and to learn by simple training. ANN is well known tool and widely used in power system. An ANN model is successfully implemented here for network reconfiguration problem. A three layer feed forward ANN trained with Error Back Propagation Learning (EBPL) algorithm is studied here. A feed forward ANN works on the basis of propagation of signal in only one direction from an input stage to an output stage through intermediate neurons. Network reconfiguration problem has an extremely nonlinear relationship between different switching status and system topology. Hence, Error Back Propagation Learning 
algorithm is suitable for network reconfiguration. As the iteration grow the training error decrease and ultimately objective is satisfied.

Global Search: The ANN model is trained with different sets of switching obtained from local search. Considering all the arbitrary variation of switching states, global optimal set of switching combination is generated for ANN estimated minimum value of VSI.

For global search, three subgroup of processing elements via, input layer, hidden layer and output layer are described as follows.

Input Layer: Normally heuristic knowledge is required for choosing of input variables. Different sets of switching combination obtained from local search respect to their values of VSI are used to find out optimum system topology.

Hidden layer: Hidden layers are used in ANN to increase computational power. In our simulation one hidden layer with five neurons has generated quite satisfactory results. Transigmoidal activation functions have been used for all neurons in the hidden layer in this ANN framework.

Output Layer: In our experiment one output layer is used. The sigmoidal activation function has applied. A proper scaling of the input and output variables have done as the output of chosen activation function was in the range of zero to one.

The EBPL algorithm is derived based on the concept of the gradient descent search to minimize the error through the adjustment of weights. For a three layer ANN withIinputs ( $\mathrm{I}=1$ used in this paper), one hidden layer with $J$ neurons and Koutput neurons ( $\mathrm{K}=3$ used in this paper), the error function is defined as follows:

$$
E_{p}=\frac{1}{2} \sum_{k=1}^{K}\left(d_{p k}-o_{p k}\right)^{2}
$$

Where $d_{p k}$ and $o_{p k}$ are the desired and actual outputs of the ANN for pattern $p$, respectively; $p=1,2, \ldots \ldots . P$ with $P$ being the number of training patterns.

The global optimum set of switching combination is generated by ANN when the value of VSI is almost minimum for whole system. In the form of mapping, the nonlinear relationship between the switching combination and optimal voltage stable configuration is as follows \{Local best switching combination for different loops $\} \rightarrow$ Different value of VSI for arbitrary switching options $\} \rightarrow$ Estimated minimum value of voltage stability indicator $\} \rightarrow$ \{Global set of switching combination for desired configuration $\}$.

\section{Simulation Of System And Results}

Proposed reconfiguration methodology has been tested on a 52 bus, $11 \mathrm{kV}$ practical distribution network with three main feeders [4]. The schematic diagram of the test system is shown in Figure8 (Appendix). System data of base configuration are tabulated below.

Conductor type: ACSR

Line resistance: $0.0086 \mathrm{p} . \mathrm{u} / \mathrm{km}$

Line reactance: $0.0037 \mathrm{p} . \mathrm{u} / \mathrm{km}$

The original system is simulated in MATLAB environment using Newton-Raphson load flow algorithm. The system is reduced to its equivalent two bus system model and voltage stability condition of the whole system is measured using proposed as $L=0.5710$. Active and reactive power losses are calculated from load flow solution as $P_{\text {loss }}=0.854 \mathrm{MW}$ and $Q_{\text {loss }}=0.355$ MVAR respectively. 
Partha Kayal, et al.

Table 1. Line and load data of practical 52 bus system

\begin{tabular}{|c|c|c|c|c|}
\hline Sending Bus & Receiving Bus & $\begin{array}{c}\text { Line Length } \\
\text { (kms) }\end{array}$ & $\begin{array}{c}\text { Receiving Bus Real } \\
\text { Power (kW) }\end{array}$ & $\begin{array}{c}\text { Receiving Bus } \\
\text { Reactive Power } \\
\text { (kVAR) } \\
\end{array}$ \\
\hline 1 & 2 & 3.0 & 81 & 39 \\
\hline 2 & 3 & 5.0 & 135 & 65 \\
\hline 2 & 4 & 1.5 & 108 & 52 \\
\hline 4 & 5 & 1.5 & 108 & 52 \\
\hline 4 & 6 & 1.0 & 27 & 13 \\
\hline 6 & 7 & 2.0 & 54 & 26 \\
\hline 6 & 8 & 2.5 & 135 & 65 \\
\hline 8 & 9 & 3.0 & 81 & 39 \\
\hline 9 & 10 & 5.0 & 67 & 32 \\
\hline 10 & 11 & 1.5 & 27 & 13 \\
\hline 11 & 12 & 1.0 & 27 & 13 \\
\hline 11 & 13 & 5.0 & 108 & 52 \\
\hline 12 & 14 & 3.5 & 54 & 26 \\
\hline 12 & 15 & 4.0 & 94 & 45 \\
\hline 10 & 16 & 1.5 & 67 & 33 \\
\hline 16 & 17 & 6.0 & 67 & 33 \\
\hline 16 & 18 & 5.0 & 108 & 52 \\
\hline 18 & 19 & 4.0 & 81 & 39 \\
\hline 1 & 20 & 1.0 & 108 & 52 \\
\hline 20 & 21 & 1.5 & 94 & 46 \\
\hline 21 & 22 & 3.0 & 81 & 39 \\
\hline 22 & 23 & 5.0 & 108 & 52 \\
\hline 23 & 24 & 2.5 & 108 & 52 \\
\hline 22 & 25 & 3.0 & 102 & 50 \\
\hline 25 & 26 & 4.0 & 41 & 20 \\
\hline 20 & 27 & 1.0 & 108 & 52 \\
\hline 27 & 28 & 1.5 & 162 & 79 \\
\hline 28 & 29 & 2.5 & 68 & 33 \\
\hline 27 & 30 & 4.0 & 68 & 33 \\
\hline 30 & 31 & 5.0 & 95 & 46 \\
\hline 1 & 32 & 4.0 & 41 & 20 \\
\hline 32 & 33 & 5.0 & 121 & 59 \\
\hline 33 & 34 & 4.0 & 41 & 20 \\
\hline 33 & 35 & 3.5 & 41 & 20 \\
\hline 35 & 36 & 4.0 & 135 & 66 \\
\hline 36 & 37 & 2.5 & 81 & 40 \\
\hline 35 & 38 & 2.0 & 68 & 33 \\
\hline 33 & 39 & 2.5 & 95 & 46 \\
\hline 39 & 40 & 2.0 & 108 & 52 \\
\hline 39 & 41 & 2.5 & 41 & 20 \\
\hline 41 & 42 & 3.0 & 95 & 46 \\
\hline 41 & 43 & 4.5 & 27 & 13 \\
\hline 43 & 44 & 5.0 & 122 & 59 \\
\hline 41 & 45 & 1.5 & 108 & 52 \\
\hline 45 & 46 & 3.5 & 81 & 39 \\
\hline 45 & 47 & 2.5 & 68 & 33 \\
\hline 47 & 48 & 1.5 & 41 & 20 \\
\hline 47 & 49 & 1.5 & 68 & 33 \\
\hline 49 & 50 & 4.0 & 81 & 39 \\
\hline 49 & 51 & 1.5 & 108 & 52 \\
\hline 51 & 52 & 1.0 & 41 & 20 \\
\hline
\end{tabular}


Local search: In local search method six different loops are studied separately. Line data of six tie line considered here to form loops are given in Table-2.

Table 2. Line data of Tie lines

\begin{tabular}{|c|c|c|}
\hline Sending Bus & Receiving Bus & Approximate Line Length (kms) \\
\hline 33 & 47 & 6.5 \\
\hline 32 & 35 & 5.0 \\
\hline 35 & 43 & 6.0 \\
\hline 20 & 25 & 5.5 \\
\hline 6 & 16 & 7.5 \\
\hline 8 & 11 & 4.0 \\
\hline
\end{tabular}

For the first loop, S-2, S-3, S-4, S-5 are sectionalize switches (NC) and S-1 is tie switch (NO). At normal condition NCs are closed NO is open position. Checking all the switching combination for Loop-I, optimal configuration is achieved by closing switch S-1 between bus 33 to 47 and opening switch S-2 between bus 45 to 47 . The corresponding values of VSI and power losses for new configuration are as

$$
\begin{aligned}
& \mathrm{L}=0.5111 \\
& P_{\text {loss }}=0.741 \mathrm{MW} \text { and } Q_{\text {loss }}=0.317 \mathrm{MVAR} .
\end{aligned}
$$

Repeating the same procedure as stated before, optimal radial configuration for Loop-II is obtained for set of NC switch $\{$ S-6, S-7 $\}$ and NOswitch S-8. For other four loops also same method is applied to improve voltage stability. In the following table improved voltage stability condition of network, the active and reactive power losses corresponding to best local search switching option is mentioned.

Table 3. Six different switching options, valuesof L, $P_{\text {loss }}$ and $Q_{\text {loss }}$ for optimal local search

\begin{tabular}{|c|c|c|c|c|}
\hline $\begin{array}{c}\text { Tie Switch } \\
\text { Closed }\end{array}$ & $\begin{array}{c}\text { Sectionalize Switch } \\
\text { Open }\end{array}$ & Value of $\mathbf{L}$ & $P_{\text {loss }}(\mathbf{M W})$ & $Q_{\text {loss }}(\mathbf{M V A R})$ \\
\hline S-1 & S-2 & 0.5111 & 0.741 & 0.317 \\
\hline S-6 & S-8 & 0.5017 & 0.720 & 0.299 \\
\hline S-9 & S-10 & 0.5506 & 0.815 & 0.388 \\
\hline S-11 & S-14 & 0.5686 & 0.849 & 0.353 \\
\hline S-15 & S-19 & 0.5350 & 0.779 & 0.323 \\
\hline S-20 & S-21 & 0.5434 & 0.797 & 0.330 \\
\hline
\end{tabular}

Global Search:The global search ANN model has trained with close switching sets $\{\mathrm{S}-1$, S-3, S-4, S-5\}, \{S-6, S-7\}, \{S-4, S-5, S-8, S-9\}, \{S-11, S-12, S-13\}, \{S-15, S-16, S-17, S-18\}, $\{\mathrm{S}-17, \mathrm{~S}-18, \mathrm{~S}-20\}$ corresponding to the values of VSI 0.5111, 0.5017, 0.5506, 0.5686, 0.5350, 0.5434 from local search. After randomly choosing switching states maintaining radial structure, the different voltage stability levels using VSI are compared by ANN. Global best set of close switching option $\{$ S-1, S-3, S-4, S-5, S-6, S-7, S-9, S-11, S-12, S-13, S-15, S-16, S-17, S-18, S-20 is obtained for minimum value of VSI, $L_{i}=0.3664$. Figure. 2 and Figure. 3 show ANN simulated training and result graph 


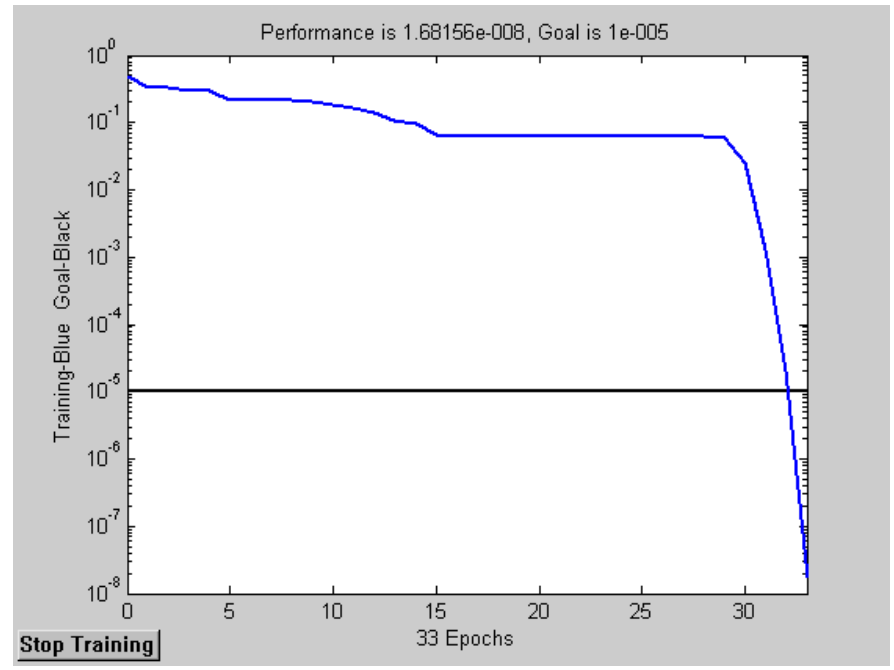

Figure 2. ANN model training graph

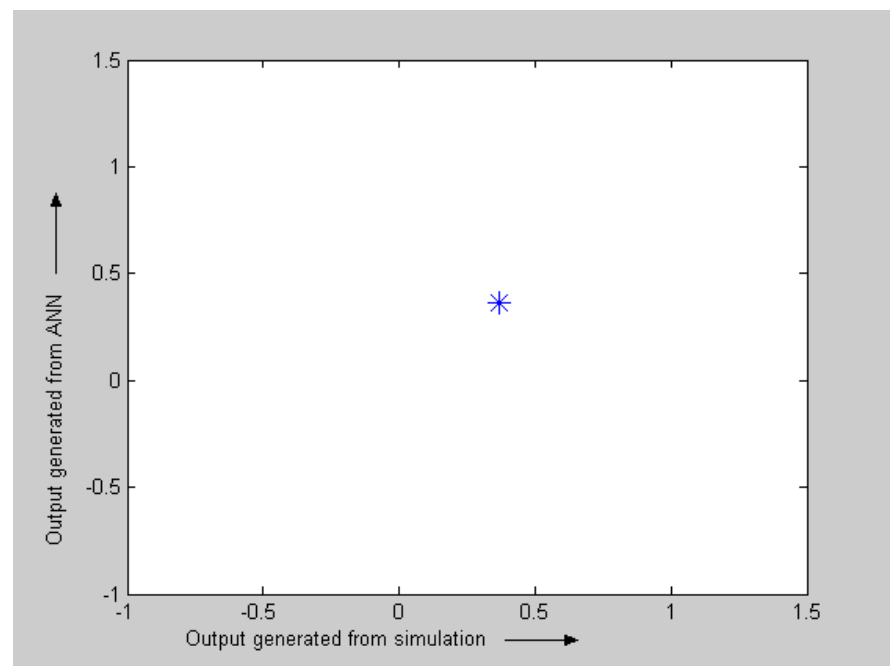

Figure 3. ANN generated output Vs Simulation output plot

Mean Square Error, MSE $=1.68156 \times 10^{-8}$ is generated from ANN simulation which also strongly recommends the desired configuration.

After reconfiguration distribution power losses and value of VSI of the system are reduced and tabulated in Table 4.

Table 4. Comparison of VSI, active and reactive power losses between before reconfiguration and after reconfiguration

\begin{tabular}{|l|c|c|c|}
\hline & Value of L & $\boldsymbol{P}_{\text {loss }}(\mathbf{M W})$ & $Q_{\text {loss }}($ MVAR) \\
\hline Before Reconfiguration & 0.5710 & 0.854 & 0.355 \\
\hline After Reconfiguration & 0.3664 & 0.485 & 0.199 \\
\hline
\end{tabular}


Voltage magnitude of the buses for optimal configuration are also be noted and compared with voltages before reconfiguration.

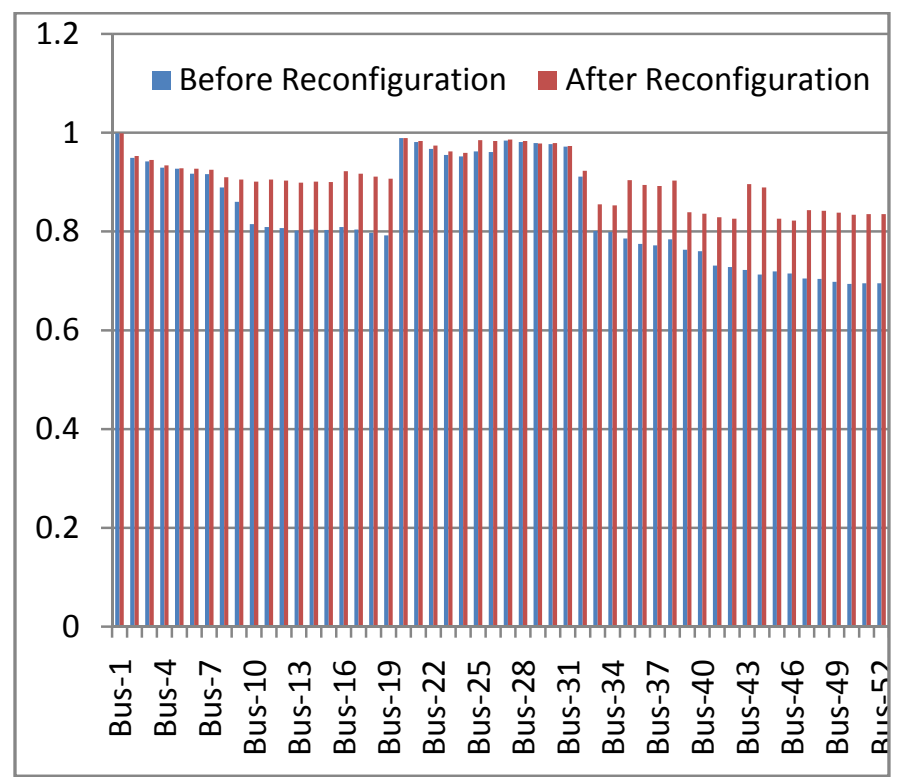

Figure 4. Comparison of bus voltages between before reconfiguration and after reconfiguration

From Figure4,it is cleared that voltage magnitudes are increased at almost all the buses. Before reconfiguration, minimum bus voltage in the system was found at Bus-50 and its value was 0.694p.u.After reconfiguration minimum bus voltage in the system is found at Bus-50 and its value is raised to 0.810 p.u.

Three case studies with random variation of loads are also presented in this paper.

Case 1: Loads are increased 50\% at Bus-11, Bus-14, Bus-15, Bus-21, Bus-22, Bus-28, Bus-39, Bus-40and Bus-43 in case1.

Table 5. Data of L, $P_{\text {loss }}, Q_{\text {loss }}$ for before and after reconfiguration for $50 \%$ increased loads at buses 11, 14, 15, 21, 22, 28, 39, 40, 43

\begin{tabular}{|l|c|c|c|}
\hline & Value of L & $P_{\text {loss }}$ (MW) & $\begin{array}{c}Q_{\text {loss }} \\
\text { (MVAR) }\end{array}$ \\
\hline $\begin{array}{l}\text { Before } \\
\text { Reconfiguration }\end{array}$ & 0.6292 & 1.058 & 0.441 \\
\hline $\begin{array}{l}\text { After } \\
\text { Reconfiguration }\end{array}$ & 0.3965 & 0.582 & 0.240 \\
\hline
\end{tabular}




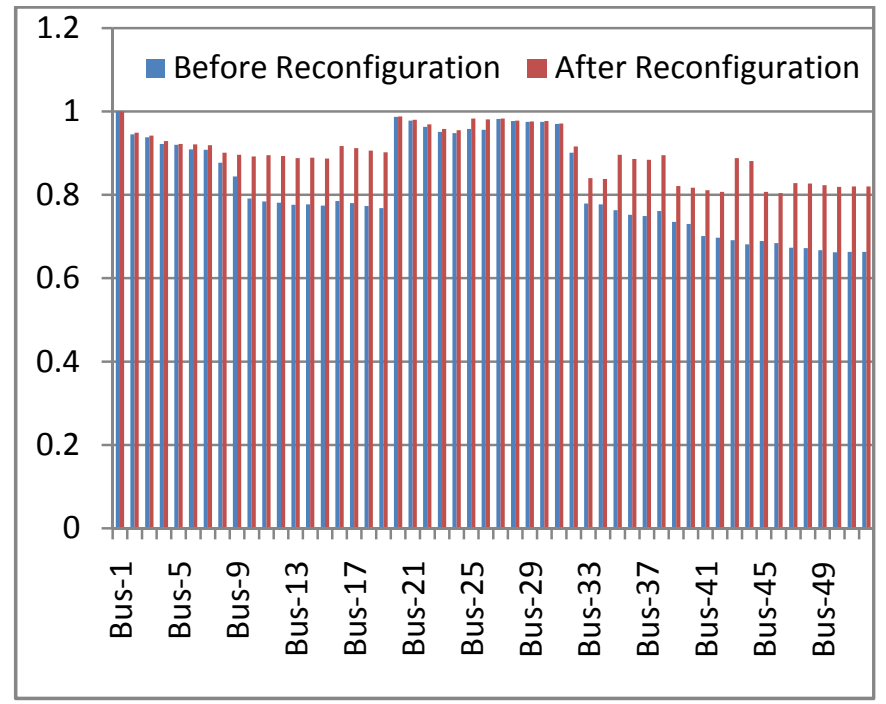

Figure 5. Variation of bus voltages of 52 busesfor before and after reconfiguration for case-1

Minimum value of magnitude of bus voltage in the system was at Bus-50 and its value was 0.662 p.u which hasrisento 0.795p.u after reconfiguration.

Case 2: For this case loads are increased $50 \%$ at buses 10, 23, 29, 30, 35, 37 and decreased $50 \%$ at buses $18,24,42$. .

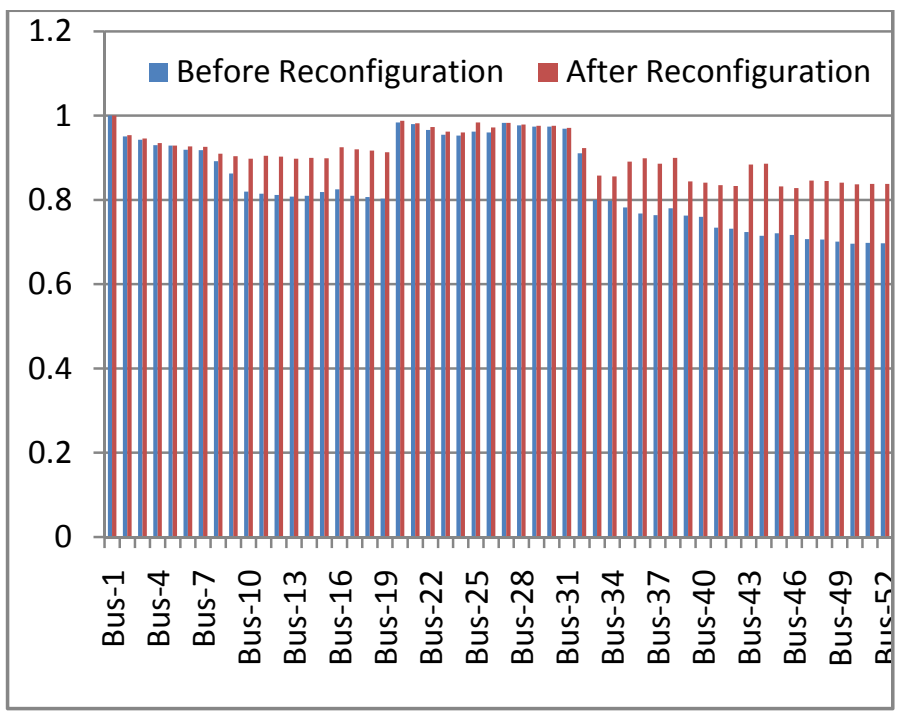

Figure 6. Different values of bus voltages for before and after reconfiguration

In this case lowest value of bus voltage in the network before reconfiguration was obtained as 0.696p.u at Bus-50. But, after reconfiguration bus voltage at Bus-50 is increased at 0.813p.u.

Case 3: In this case study loads are increased $50 \%$ at Bus-5, Bus-7, Bus-8 and decreased 50\% at Bus-13, Bus-26, Bus-27, Bus-33, Bus-46, Bus-48. 
Table 6. Values of L, $P_{\text {loss }}$, $Q_{\text {loss }}$ before and after reconfiguration for case-2

\begin{tabular}{|l|c|c|c|}
\hline & Value of L & $P_{\text {loss }}$ (MW) & $\begin{array}{c}Q_{\text {loss }} \\
\text { (MVAR) }\end{array}$ \\
\hline $\begin{array}{l}\text { Before } \\
\text { Reconfiguration }\end{array}$ & 0.5595 & 0.843 & 0.350 \\
\hline $\begin{array}{l}\text { After } \\
\text { Reconfiguration }\end{array}$ & 0.3567 & 0.476 & 0.196 \\
\hline & & & \\
\hline
\end{tabular}

Table 7. Comparison of $\mathrm{L}, P_{\text {loss }}, Q_{\text {loss }}$ for before and after reconfiguration for $50 \%$ increased loads at buses 5, 7, 8 and 50\% decreased at buses 13, 26, 27, 33, 46, 48

\begin{tabular}{|l|c|c|c|}
\hline & Value of L & $P_{\text {loss }}$ (MW) & $\begin{array}{c}Q_{\text {loss }} \\
\text { (MVAR) }\end{array}$ \\
\hline $\begin{array}{l}\text { Before } \\
\text { Reconfiguration }\end{array}$ & 0.5221 & 0.741 & 0.308 \\
\hline $\begin{array}{l}\text { After } \\
\text { Reconfiguration }\end{array}$ & 0.3460 & 0.441 & 0.182 \\
\hline
\end{tabular}

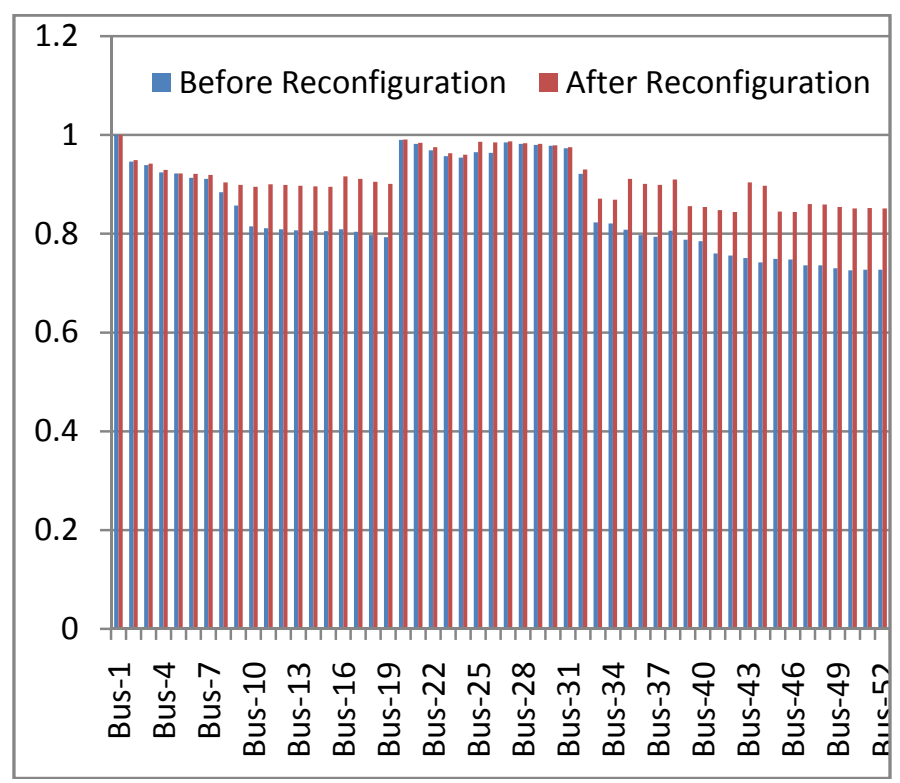

Figure 7. Variation of bus voltages of different buses for before and after reconfiguration for case-3

Minimum value of bus voltage magnitude in the network was previously 0.726 p.u at Bus50 which has risento 0.829 p.u by network reconfiguration.

The results of the above all case studies completely support for the proposed reconfiguration.In all the cases maximum voltage stable and minimum power loss network are obtained for switching set of NC \{ S-1, S-3, S-4, S-5, S-6, S-7, S-9, S-11, S-12, S-13, S-15, S16, S-17, S-18, S-20\} and NO \{S-2, S-8, S-10, S-14, S-19, S-21\}. Also from Fig5, Fig6, Fig7, it is observed that values of voltage magnitudes for the most of the buses are maximized after reconfiguration. 


\section{Conclusion}

Developed index has measured the level of voltage stability for the whole distribution system. This paper further reveals the optimal reconfiguration technique based on a new heuristic approach. Using developed VSI, an ANN model is simulated and an optimal configuration is attained with opening of switch S-2, S-8, S-10, S-14, S-19, S-21 and closing of switch S-1, S-3, S-4, S-5, S-6, S-7, S-9, S-11, S-12, S-13, S-15, S-16, S-17, S-18, S-20. After proper reconfiguration, voltage stability of the system is improved significantly. Total power loss of the system is reduced from 0.854+j0.355MVA to 0.485+j0.199 MVA. After reconfiguration voltage profiles of most of the buses are improved. Different case studies with arbitrary variation of loads also show enhancement of voltage stability and reduction of losses for implemented new configuration of network.

\section{References}

[1]. Augugliaron et al, 2004. Voltage regulation and power loss minimization in automated distribution network by an evolutionary multi objective approach. IEEE trans. on Power System, Vol. 19, No. 3, pp. 1516-1527.

[2]. Venkatesh et al, 2004. Optimal reconfiguration of radial distribution system to maximize loadability. IEEE Trans. on Power System, Vol. 19, No. 1, pp. 260-266.

[3]. K. Chanda et al, 2004. Development of global voltage security indicator(VSI) and role of SVC on it in longitudinal power supply(LPS) system. Elsevier, Electrical Power and System Research,pp. 68, 1-9.

[4]. Thukaram et al, 2005. Artificial neural network and support vector machine approach for locating faults in radial distribution system. IEEE Trans. on Power Delivery, Vol. 20, No. 2, pp. 710-721.

[5]. Gubina, B. Strmcnik, 1997. A simple approach to voltage stability assessment in radial network.IEEE Trans. on Power System, Vol. 12, No. 3, pp. 1121-1128.

[6]. B. Jasmon and L. H. C. C. Lee, 1991. Maximizing voltage stability in distribution networks via loss minimization. J. Electr. Power Energy System, pp. 148-152.

[7]. Kim et al, 1993. Artificial Neural Network Based Feeder Reconfiguration for Loss Reduction in Distribution Systems. IEEE Trans on Power Delivery, Vol. 8, no 3, pp. 1356-1366.

[8]. Salazar et al, 2006. Artificial neural network and clustering techniques applied in reconfiguration of distribution system. IEEE Trans. on Power Del. Vol. 21, No. 3, pp. 1735-1742.

[9]. Ismail K. Said et al, 2009. Neural network based load balancing and reactive power control by static VAR compensator. Int. J. of Computer and Electrical Engineering, Vol. 1, No. 1, pp. 1793-8198.

[10]. Joong-Rin Shin et al, 2007. A new optimal routing algorithm for loss minimization and voltage stability improvement in radial power systems. IEEE Trans. on Power System, Vol. 22, No. 2, pp. 648-657.

[11]. K. Nara et al, 1992. Implementation of genetic algorithm for distribution system loss minimum reconfiguration, IEEE Transaction on Power System, Vol. 7, No. 3, pp. 10441051.

[12]. M. A. Kashem et al, 2000. A new approach of distribution system reconfiguration for loss minimization. Electrical Power and Energy Systems, Elsevier, 22 (2000), pp. 269-276.

[13]. M.E.Baran, F.F. Wu, 1989. Network reconfiguration in distribution systems for loss reduction and load balancing. IEEE Trans. on Power Delivery, Vol. 4, No. 2, 1401-1407.

[14]. M. Chkravorty, D. Das, 2001. Voltage stability analysis of radial distribution network. Electrical Power and Energy Systems, Elsevier, Vol. 23, pp. 129-135.

[15]. S. K. Goswami, S. K. Basu, 1992. A new algorithm for the reconfiguration of of distribution feeders for loss minimization. IEEE Trans. on Power Delivery, Vol. 7, pp. 1338-1342. 


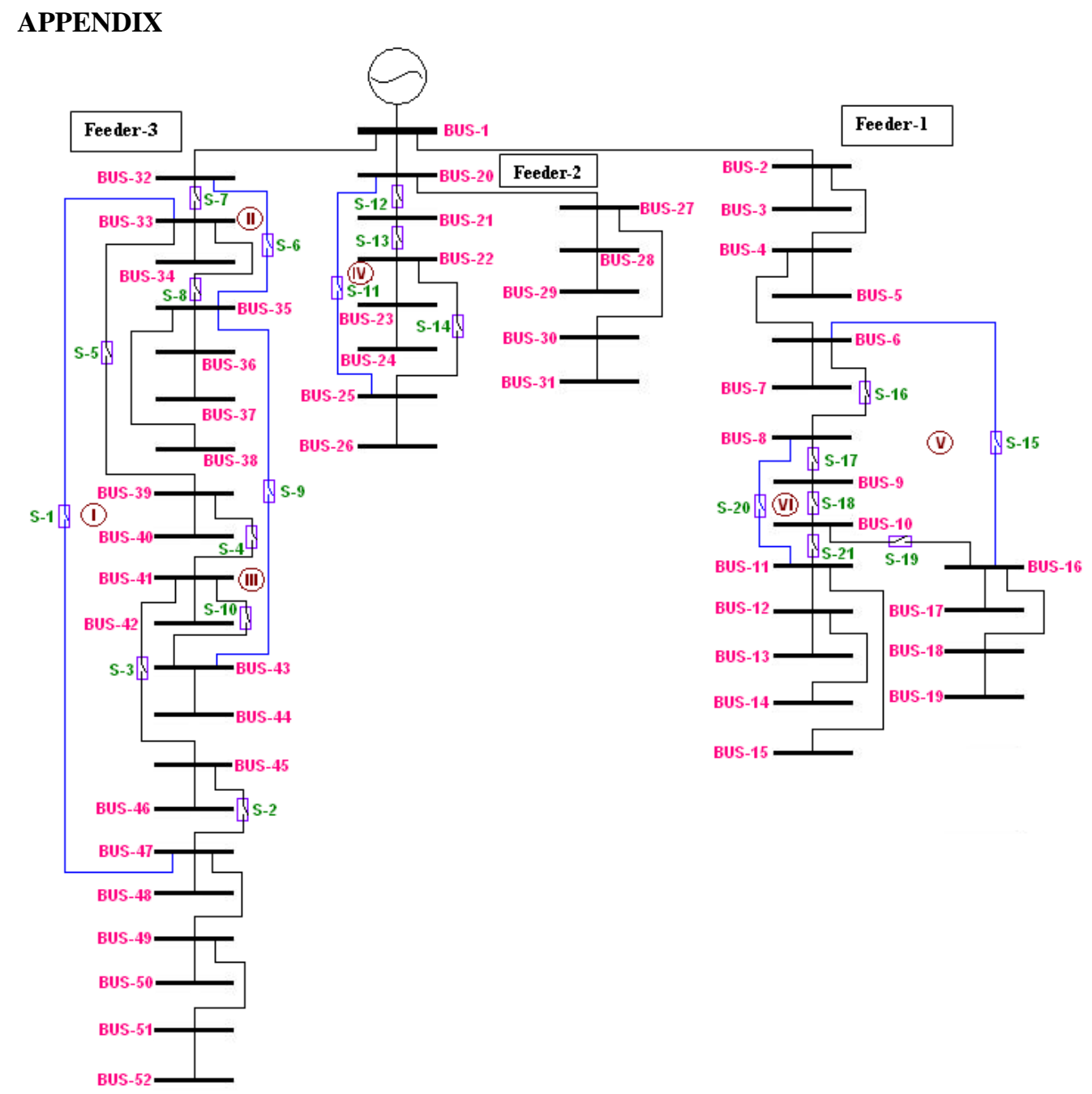

Figure 8. Practical 52-bus radial distribution system with bus-1 as source bus 


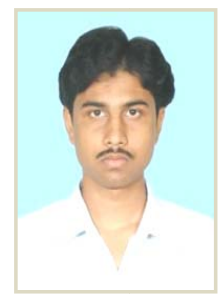

Partha Kayal has completed his B.Tech in Electrical Engineering from West Bengal University of Technology, India in 2008. He has completed M.E in Electrical Engineering with specialization in Power System in 2010 from Bengal Engineering and Science University, Shibpur, India and now he is doing Ph.D there. He has published few papers in National and International Conferences and Journals. His current research interest includes Power System Stability, Microgrid, Network Reconfiguration, Distributed Generation etc.

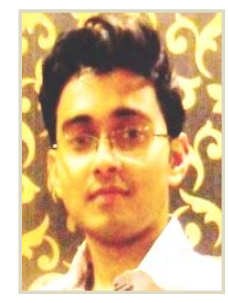

Sayonsom Chanda has graduated from NIT Durgapur, with a First Class Distinction as a Bachelor of Technology in Electrical Engineering in 2012. During his B.Tech years, he has developed a desire to work in areas of renewable energy and modernization of power distribution methods. Now he is going to work on Smart Grids, modern power grids and electricity distribution in SGDIRL in Washington State University, Pullman, USA. He has published some papers in National and International Conferences.

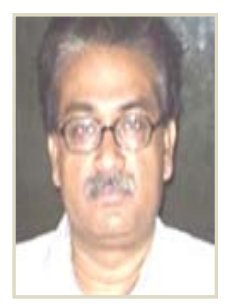

Chandan Kumar Chanda is a Professor of Electrical Engineering at Bengal Engineering \& Science University, Shibpur erstwhile Bengal Engineering College, Shibpur. He was awarded his $\mathrm{PhD}$ in Engineering from Bengal Engineering \& Science University itself in 2003. He received his M.Tech degree from the Department of Electrical Engineering from Indian Institute of Technology Kharagpur in 1989. Prior to that, he received his Bachelor in Engineering with Honors from Regional Engineering College (presently National Institute of Technology Durgapur) from the Department of Electrical Engineering in 1983. He has been associated with the academia and research for the last 24 years. He was formerly a lecturer in Electrical Engineering in Regional Engineering College Durgapur, before joining Bengal Engineering College, Shibpur in 1991. He has over 50 peer-reviewed publications in national and international journals and conferences. 